\title{
Isolated lunate dislocation
}

\author{
Satvik N Pai @ (), Mohan M Kumar
}

Orthopaedic Surgery, Sri Ramachandra Institute of Higher Education and Research, Chennai, Tamil Nadu, India

\section{Correspondence to Dr Satvik N Pai: satvik.pai@gmail.com}

Accepted 22 February 2022

\section{DESCRIPTION}

A man in his 50s had a fall from a motorcycle and sustained an injury to his left wrist. On examination, he was found to have tenderness over his wrist with range of movements of the wrist being restricted due to pain. On making a fist, the second metacarpal head was found to be in line with the third and found metacarpal heads (Murphy's sign positive).

Posteroanterior radiograph of the wrist was performed. It was confirmed to be a true posteroanterior view by the presence of the ulnar styloid medial to the ulnar shaft (figure 1A). The lunate was found to be malaligned, overlapping the scaphoid, triquetrum and capitate (figure 1B). Gilula's second arc corresponding to the distal articular surface of the proximal carpal row was found to be disrupted (figure 1C). Lunate was found to be overlapping with the capitate, indicating the proximal migration of the capitate (figure 1D). A lateral radiograph of the wrist was performed. It was confirmed to be a true lateral view by the ulnar head being superimposed over the distal radius, overlap of second-fifth metacarpal shafts and the volar border of pisiform lying in the middle third of the scaphoid (figure 2A). The lunate was found to be volarly dislocated (figure 2B). The spilled teacup sign was noted (figure 2C). The radius and capitate were found to be aligned with the lunate volarly displaced and

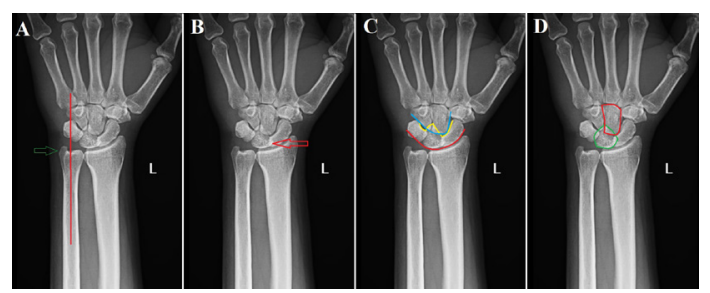

Figure 1 Posteroanterior radiograph of the wrist. (A) Confirming it to be a true posteroanterior view by the presence of the ulnar styloid (green arrow) medial to the ulnar shaft (red line). This can distinguish it from an anteroposterior view of the wrist in which the ulnar styloid would lie in line with the ulnar shaft. (B) Malaligned lunate. Lunate appears to be overlapping the scaphoid, with obliteration of the normal scapholunate gap (red arrow). (C) Gilula's arcs. The first arc (red) drawn along the proximal articular surface of the scaphoidlunate-triquetrum was found to be a smooth curve. The second arc (yellow) drawn along the distal articular surface of the scaphoi-d-lunate-triquetrum was found to be disrupted. The third arc (blue) drawn along the proximal articular surface of the capitate-hamate was found to be a smooth curve. (D) Lunate (green) was found to be overlapping with the capitate (red), which should normally not overlap.

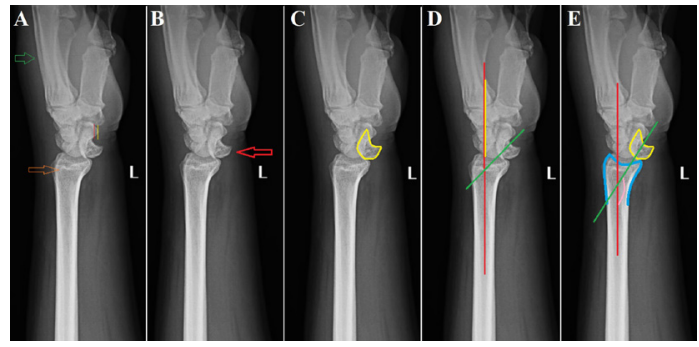

Figure 2 Lateral radiograph of the wrist. (A) Confirmed to be a true lateral view by the ulnar head being superimposed over distal radius (orange arrow), superimposition of second through fifth metacarpals (green arrow), volar border of pisiform (red line) lying dorsal to the volar border of the scaphoid (yellow line). (B) Lunate found to be volarly displaced. (C) Spilled teacup sign - volar displacement and angulation of lunate (yellow). (D) Radial axis (red line) and capitate axis (yellow line) were found to be in line, only the lunate displaced volarly with its axis also angulated volarly (green line). (E) Radiolunate angle (pink) was found to be increased. Radial axis (red line) drawn along the midline of the distal radius (blue). Lunate axis (green line) drawn along the midline of lunate (yellow). Radiolunate angle measured between the two radial axis and lunate axis, normally should be less than $15^{\circ}$.

\section{Patient's perspective}

I visited a different hospital at first, where I was told that there was no fracture and the X-ray was normal. However, I still had pain and swelling in my wrist. So after 1 week, I visited this hospital, where they told me I have a dislocation of a bone in my wrist which is causing the pain.

\section{Learning points}

- Isolated lunate dislocations represent a rare subsection of perilunate dislocations which are often undiagnosed due to the rest of the carpus remaining aligned.

- Careful analysis of radiographs is required for diagnosis, indicated by disruptions of Gilula's arc, lunocapitate overlap on posteroanterior radiographs and spilling teacup sign, increased radiolunate angle on lateral radiographs.

- Neglected lunate dislocations can lead to median nerve dysfunction, carpal instability, avascular necrosis of lunate and arthritis. 
malaligned (figure 2D). The radiolunate angle which is normally less than $15^{\circ}$ was found to be increased (figure $2 \mathrm{E}$ ). No fractures were noted in any of the radiographs. These were the typical radiological features of an isolated lunate dislocation. He was advised to undergo open reduction, repair of ligaments and fixation. However, he was not willing for surgical management and was lost to further follow-up.

Perilunate dislocations are rare traumatic injuries of the wrist. They usually occur due to a fall with the wrist in extension, ulnar deviation and intercarpal supination. They are classified according to the Mayfield classification system. ${ }^{1}$ Among these, lunate dislocations represent only the type IV injury, which are among the most unstable. Isolated lunate dislocations are often unrecognised as the rest of the carpus remains aligned. ${ }^{2}$ The rate of incorrect diagnosis is reported to be as high as $25 \% .^{3}$ Careful analysis of radiographs is therefore required for its diagnosis. Neglected lunate dislocations can lead to median nerve dysfunction, carpal instability, avascular necrosis of lunate and arthritis. ${ }^{4}$

Contributors SP obtained the digital images of radiographs and was responsible for the writing of the draft of the manuscript. MK was the chief orthopaedic surgeon under whom the patient was evaluated and guided the entire process of preparation of the article, including reviewing the article. SP and MK were both involved in the evaluation of the patient, analysis of radiographs and patient care.

Funding The authors have not declared a specific grant for this research from any funding agency in the public, commercial or not-for-profit sectors.

Competing interests None declared.

Patient consent for publication Consent obtained directly from patient(s).

Provenance and peer review Not commissioned; externally peer reviewed.

Case reports provide a valuable learning resource for the scientific community and can indicate areas of interest for future research. They should not be used in isolation to guide treatment choices or public health policy.

\section{ORCID iD}

Satvik N Pai http://orcid.org/0000-0002-3621-150X

\section{REFERENCES}

1 Mayfield JK. Mechanism of carpal injuries. Clin Orthop Relat Res 1980;149:45-54.

2 Garner M, Rudran B, Khan A, et al. Lunate dislocations: anatomy, diagnosis and management. Br J Hosp Med 2021;82:1-10.

3 Muppavarapu RC, Capo JT. Perilunate dislocations and fracture dislocations. Hand Clin 2015;31:399-408.

4 Goodman AD, Harris AP, Gil JA, et al. Evaluation, management, and outcomes of lunate and Perilunate dislocations. Orthopedics 2019;42:e1-6.

Copyright 2022 BMJ Publishing Group. All rights reserved. For permission to reuse any of this content visit

https://www.bmj.com/company/products-services/rights-and-licensing/permissions/

BMJ Case Report Fellows may re-use this article for personal use and teaching without any further permission.

Become a Fellow of BMJ Case Reports today and you can:

- Submit as many cases as you like

- Enjoy fast sympathetic peer review and rapid publication of accepted articles

- Access all the published articles

- Re-use any of the published material for personal use and teaching without further permission

Customer Service

If you have any further queries about your subscription, please contact our customer services team on +44 (0) 2071111105 or via email at support@bmj.com.

Visit casereports.bmj.com for more articles like this and to become a Fellow 